\title{
PSICOLOGIA E LETRAS LIBRAS: UM ENCONTRO NA BUSCA POR UMA EDUCAÇÃO INCLUSIVA NO ENSINO SUPERIOR
}

\author{
Psychology and Lyrics: a meeting in the search for Inclusive Education in Higher Education \\ Psicología y Letras Libras: un encuentro en la búsqueda por una Educación Inclusiva en \\ la Enseñanza Superior
}

Denise Mesquita de Melo Almeida*

Janete de Melo Nantes**

\section{Resumo}

Discute-se neste texto a promoção da Educação Inclusiva no Ensino Superior por meio do relato de uma experiência formativa que inaugurou a parceria entre o Curso de Psicologia da Faculdade de Ciências Humanas (FCH), o Curso de Licenciatura em Letras: Língua Portuguesa/Libras da Faculdade de Educação a Distância (EaD) e o Núcleo Multidisciplinar para Inclusão e Acessibilidade da Universidade Federal da Grande Dourados (NuMIAc). Com intuito de promover a inclusão de estudantes com deficiências, implementou-se uma proposta de estágio supervisionado que, a um só tempo, inscreveu a educação inclusiva no processo de formação inicial de psicólogos; contribuiu para a reflexão sobre o perfil do egresso do curso de Letras Libras; e subsidiou encaminhamentos institucionais necessários à implantação de políticas de acessibilidade e permanência qualificada a estudantes autodeclarados com deficiências na universidade.

PALAVRAS-CHAVE: Inclusão. Ensino Superior. Psicologia. Libras.

\begin{abstract}
This text discusses the promotion of Inclusive Learning in Higher Education through the report of a formative experience that launched the partnership between the Psychology Course of the College of Human Sciences (FCH) and the Bachelor's Degree Course in Languages: Portuguese / Libras (The Brazilian Sign Language) of the Open and Distance Learning (ODL) with the Multidisciplinary Nucleus for Inclusion and Accessibility of the Federal University of Grande Dourados (NUMIAc). In order to promote the inclusion of students with disabilities, a supervised internship proposal was implemented, which at the same time included inclusive education in the initial training of psychologists; contributed to the observation on the profile of the graduate of the Libras Course; and, subsidized institutional funds necessary to the implementation of policies of accessibility and qualified permanence to self-declared students with disabilities in the university.
\end{abstract}

KEYWORDS: Inclusion. Higher education. Psychology. Libras.

\section{Resumen}

En este texto se debate la promoción de la Educación Inclusiva en la Enseñanza Superior por medio del relato de experiencia de una experiencia formativa que inauguró la asociación entre el Curso de

\footnotetext{
* Psicóloga, mestre e doutora em Educação. Professora adjunta no Curso de Psicologia FCH/UFGD.

** Pedagoga e intérprete de Libras, mestre em Educação. Professora assistente no Curso de Letras Libras $\mathrm{EaD/UFGD.}$
} 
Psicología de la facultad de Ciencias Humanas $(\mathrm{FCH})$ y el Curso de Licenciatura en Letras: Lengua Portuguesa/Libras de la Facultad de Educación a Distancia (EaD) con el Núcleo Multidisciplinar para Inclusión y Accesibilidad de la Universidad Federal de Grande Dorados (NUMIAc). Con vistas a promoción inclusiva de estudiantes con discapacidad se implementó una oferta de prácticas supervisadas que, al mismo tiempo, inscribió la educación inclusiva en el proceso de formación inicial de psicólogos; contribuyó para reflexión sobre el perfil del egreso del curso Letras Libras; y, subvencionó encaminamientos institucionales importantes hasta la implementación de políticas de accesibilidad y permanencia cualificada de estudiantes que se declaran con discapacidad en la universidad.

PALABRAS CLAVE: Inclusión. Enseñanza Superior. Psicología. Libras

\section{INTRODUÇÃO}

Neste estudo, propomo-nos a uma reflexão a respeito do encontro entre diferentes iniciativas implementadas no seio de uma universidade pública, visando à promoção de uma Educação Inclusiva no ensino superior. Especificamente, referimo-nos à experiência resultante de uma articulação de esforços que se consolidaram no estabelecimento de uma parceria, na Universidade Federal da Grande Dourados (UFGD), entre o Curso de Psicologia da Faculdade de Ciências Humanas (FCH), o Curso de Licenciatura em Letras: Língua Portuguesa/Libras da Faculdade de Educação a Distância $(\mathrm{EaD})$ e o Núcleo Multidisciplinar para Inclusão e Acessibilidade da Universidade Federal da Grande Dourados (NuMIAc).

Tal parceria permitiu a elaboração e o desenvolvimento de uma proposta formativa realizada nos moldes de um estágio supervisionado em avaliação psicológica ao longo de um semestre no ano de 2017. Essa experiência pautou a educação inclusiva no processo de formação inicial de psicólogos, contribuiu para a reflexão sobre o perfil do egresso do curso de Letras Libras e subsidiou encaminhamentos institucionais necessários à implantação de políticas de acessibilidade e permanência qualificada a estudantes autodeclarados com deficiências na universidade em questão.

As aprendizagens geradas nesse processo justificam esse investimento reflexivo que passamos a desempenhar, abordando desde o esforço para situar a relação entre a Psicologia e a Educação Especial, sobretudo sob a perspectiva da Educação Inclusiva, a exploração da trajetória histórica de formação de intérpretes em língua de sinais e a implantação do Curso de Letras-Libras na Universidade Federal da Grande Dourados (UFGD), até chegarmos à experiência articulada na prática de estágio propriamente dita.

\section{Psicologia, educação e inclusão: alertas e desafios}

A Psicologia, a Educação e a Educação Especial são áreas do conhecimento que há muito tempo caminham juntas e construíram entre si laços bastante expressivos. Diferentes estudos sobre o surgimento da Psicologia no Brasil revelam o entrelaçamento dessa ciência com as pesquisas desenvolvidas já nos primeiros laboratórios de estudos pedagógicos existentes no País (ANTUNES, 2008; ASBAHR, 2014; VIANA, 2016; SOUZA, 2010), entre outros. Tais pesquisas apontam que, ao longo dessa história, nas intersecções produzidas entre tais áreas, os avanços alcançados pelas frentes de estudos, mesmo que individualmente, impactam fortemente o desenvolvimento da outra e, juntas, comprometem-se com o desenvolvimento mais amplo de projetos de sociedade que pretendem ajudar a construir. 
Patto (2004) relacionou as origens da Psicologia em nosso país, sobretudo no período histórico da Primeira República, a discursos médicos, jurídicos e pedagógicos comprometidos com ideais de modernização da sociedade brasileira, que tomavam como referência conceitual para a modernidade os padrões de comportamento e desenvolvimento europeus. Para a autora, o pensamento científico da época era fortemente marcado por um racismo científico inspirado nas teorias raciais geradas no primeiro mundo. De acordo com essas teorias, as raízes negras e indígenas da população brasileira degeneravam suas possibilidades de desenvolvimento social e, por conseguinte, econômicas. As alternativas apresentadas como contraponto a essa "sina" puderam ser verificadas no pensamento higienista que permeou muitas das políticas públicas adotadas em várias cidades pelo País como "parte de um projeto político de 'salvação da nacionalidade' e de 'regeneração da raça', verdadeira obsessão que tomou conta de nossos intelectuais e especialistas" (PATTO, 2004, p. 205).

A Psicologia daquele momento constituiu, talvez, o mais importante dos recursos utilizados pela Educação no enfrentamento das "desventuras" nacionais. E sobre esse ponto Patto (2004, p. 220) chama a atenção para a questão de que naquele período

[...] a adoção de explicações biopsicológicas da vida social divulgava uma versão despolitizada do estado de coisas reinante e bania qualquer referência à lógica do capital, silêncio que possibilitava a responsabilização do indivíduo pela má qualidade de sua vida e pela sua exclusão.

Os alertas apresentados pelos estudos mencionados acompanharam-nos desde o processo de elaboração à implementação e avaliação dos resultados alcançados com a atividade de Estágio Supervisionado em Avaliação Psicológica na Educação Especial, que desenvolvemos no segundo semestre do ano de 2017, no Curso de Psicologia - FCH/UFGD. Durante todo o percurso, preocupamo-nos em compreender que para o estabelecimento da interface entre a Psicologia e a Educação Especial, sob a ótica da inclusão, é preciso não perder de vista essa implicação histórica entre o curso de Psicologia e o estabelecimento da ordem utilizada para inscrever as relações sociais e de trabalho do Brasil no modo de produção que vem caracterizando a política e economia do País desde meados do século XIX. Sobretudo na conjuntura atual de nosso país, os estudos despertaram-nos a atenção para a não reprodução de práticas que pudessem resultar em atualização ou renovação de condutas que, tradicionalmente, vêm contribuindo para estigmatizações que alicerçam processos de produção de relações marcadas por desigualdade e exclusão social.

Assim, de dentro da própria Psicologia intencionamos contribuir para a promoção de rupturas em processos de exclusão social e observamos a urgência pela construção de uma sociedade menos desigual. Nesse contexto, apostamos que um percurso possível para o redirecionamento e a construção de novos pilares para a relação entre a Psicologia e a Educação Especial seria a intensificação da dedicação a essa questão específica durante o processo de formação inicial de psicólogos.

No entanto, estudos como os de Mendonza (1997) mostraram que a adesão de psicólogos na área da Educação Especial no Estado do Mato Grosso do Sul, por exemplo, por muito tempo se deu mais em razão da área como oportunidade imediata de vinculação empregatícia do que propriamente por afinidade temática. Somando-se a isso, Sousa BrazAquino et al. (2016), em análise sobre concepções e práticas de psicólogos escolares, concluíram a respeito da fragilidade da formação inicial de psicólogos para a construção de reflexões e práticas consonantes com a proposta da inclusão.

Com base nesses dados, portanto, propusemo-nos a pautar no processo de formação inicial de psicólogos a sensibilidade e o desejo de atuar na Educação Especial sob olhar da Educação Inclusiva. Lançamo-nos à tentativa de reencantar a área da Psicologia Aplicada à 
Educação Especial, agora sob nova perspectiva, como estratégia para motivar novos psicólogos a fim de que se qualifiquem e remetam esforços para o desenvolvimento desse universo de saberes aqui na região.

Entretanto, o investimento na formação profissional para promoção da Educação Inclusiva não tem sido um esforço isolado da Psicologia ou da própria Pedagogia. Destacamos, a seguir, os desafios e as possibilidades vivenciadas também no processo de formação de intérpretes de línguas de sinais.

\section{A constituição do intérprete de línguas de sinais}

A formação do intérprete de línguas de sinais, Libras, no caso do Brasil, tem sido extremamente necessária na promoção de uma educação inclusiva, especificamente no ensino superior, nesse caso tratado no presente texto.

A história da constituição do intérprete de línguas de sinais ocorreu na medida em que os surdos começaram a participar mais ativamente da sociedade. Inicialmente com caráter voluntário, essa atividade passou a ser valorizada à medida que se avançavam as conquistas dos direitos linguísticos da comunidade surda, sua participação nas discussões sociais e o reconhecimento legal de sua língua. Consequentemente, as instituições se viram obrigadas a garantir acessibilidade por meio do profissional intérprete de língua de sinais.

No Brasil, a atuação do intérprete de língua de sinais passa a ser reconhecida pela Lei Federal n..$^{\circ}$ 10.436/2002, regulamentada pelo Decreto n. ${ }^{\circ} 5.626 / 2005$, surgindo cursos de formação de tradutores e intérpretes de línguas de sinais em nível técnico, superior e pósgraduação lato sensu (especializações). Uma pesquisa na Europa concluiu que, à medida que os surdos participam mais ativamente das discussões políticas, sociais e culturais da comunidade em que vivem e lutam pelos seus direitos, mais a profissão do intérprete de línguas de sinais passa a ser valorizada e requisitada (QUADROS, 2004, p. 16).

$\mathrm{O}$ ato de interpretar envolve um ato cognitivo-linguístico, ou seja, trata-se de um processo que envolve duas línguas distintas em situações de intenção comunicativa específica. No caso do intérprete de língua de sinais, este deve realizar a interpretação da língua falada para a língua sinalizada e vice-versa.

Quando intérpretes de línguas de sinais não estão disponíveis, a interação entre surdos e pessoas que desconhecem a língua de sinais fica prejudicada. Os surdos deixam de participar de vários tipos de atividades sociais, educacionais, culturais e políticas; não avançam educacionalmente; ficam desmotivados de participar de encontros, reuniões; e não têm acesso às discussões e informações veiculadas na língua falada, sendo, portanto, excluídos da interação social, cultural e política, sem direito ao exercício de sua cidadania, sem poder se fazer "ouvir".

Considerando a realidade brasileira na qual os surdos estão matriculados em diferentes níveis de escolarização, somente é possível atender às exigências legais que determinam o acesso e a permanência do aluno na escola observando-se suas especificidades, com a presença de intérpretes de línguas de sinais.

De acordo com Quadros (2004), o intérprete de línguas de sinais que atua na área da educação apresenta um perfil específico para intermediar as relações entre os professores e os alunos, bem como entre os colegas surdos e os colegas ouvintes. No entanto, as competências e as responsabilidades desses profissionais não são tão fáceis de ser determinadas, considerando a interface com uma equipe multidisciplinar que faz parte da educação (professores, gestores, psicólogos, alunos, técnico-administrativos, entre outros funcionários). No caso do Ensino Superior, incluem os núcleos, pró-reitorias, coordenadorias etc. 
Os intérpretes de língua de sinais precisam estar preparados para atuar em qualquer circunstância na qual o surdo se envolva, e essas situações devem ser contempladas na sua formação. No entanto, nem sempre isso ocorre em virtude da recente criação de cursos para intérpretes de línguas de sinais e, mais recente ainda, a regulamentação dessa profissão pela Lei Federal n. ${ }^{\circ}$ 12.319/2010.

A UFGD atende estudantes surdos desde 2008 por meio da parceria como polo da UFSC na oferta do curso de Letras Libras Licenciatura e Bacharelado e, a partir de 2013, quando da criação do curso institucional de Licenciatura em Letras: Língua portuguesa/Libras, passa a incorporar mais de 60 estudantes surdos por intermédio das vagas prioritárias para eles.

Até então, a UFGD não possuía pessoas surdas e ouvintes falantes de Libras transitando e se integrando na vida acadêmica universitária, o que causou um impacto positivo na Universidade, abrindo caminhos para o debate sobre acessibilidade linguística, políticas linguísticas, reflexões sobre as propostas pedagógicas para educação de surdos, valorização da formação de professores surdos e o incentivo para o desenvolvimento de pesquisas e estudos da área.

O movimento do curso Letras Libras mobilizou os servidores da cidade universitária da UFGD para atender aos estudantes com mais qualidade. Nesse sentido, o restaurante universitário e a biblioteca disponibilizaram acesso aos alunos do curso. A presença do curso deu mais visibilidade às questões da comunidade surda, como a participação deles em eventos realizados pela instituição.

A partir dessa demanda criada na UFGD, realizou-se concurso para intérpretes de Libras e para docentes fluentes nessa língua e técnicos administrativos do curso de Letras Libras, oferecendo duas vagas para intérpretes, dez vagas para docentes e oito vagas para técnicos administrativos.

Foi no contexto, portanto, dessas ressignificações vividas pela universidade e pelos cursos que se deu o encontro entre a experiência formativa dos estagiários da Psicologia e o alunado do curso de Letras Libras da UFGD, a comunidade surda.

\section{A Educação Inclusiva no Ensino Superior: as parcerias, as estratégias e os impasses}

Como mencionado anteriormente, o recurso que utilizamos para sensibilizar psicólogos em formação para a atuação na Educação Inclusiva foi, primeiramente, o estabelecimento de uma parceria entre o Curso de Psicologia - FCH/UFGD e o Núcleo Multidisciplinar de Inclusão e Acessibilidade - NuMIAc/UFGD. Essa associação efetivamente deu origem à parceria entre todos os atores envolvidos nessa iniciativa e permitiu oferecer a estudantes de Psicologia a oportunidade de mergulhar na experiência da produção de saberes aplicados, contextualizados no universo do desenvolvimento de políticas educacionais inclusivas em uma universidade pública. Para isso, articulou-se a prática de Estágio em Psicodiagnóstico - Avaliação Psicológica no Contexto da Educação Especial - às ações desenvolvidas pelo Núcleo, sobretudo aquelas concernentes ao acolhimento e à escuta clínica direcionada à produção de subsídios para a elaboração dos planos de desenvolvimento acadêmico individuais de alunos autodeclarados com deficiências no ato de sua matrícula na UFGD.

De acordo com o Projeto Pedagógico do Curso de Psicologia (PPC-UFGD, 2017), a ementa do estágio previa a promoção da aprendizagem da aplicação do psicodiagnóstico e a elaboração de hipóteses diagnósticas. No conjunto, os acadêmicos precisavam ser conduzidos ao desenvolvimento de competências e habilidades necessárias à realização da triagem e do psicodiagnóstico em sua complexidade, desde o manejo da entrevista e a aplicação de técnicas 
de avaliação à elaboração de relatório qualitativo, ao planejamento de devolutiva e à condução de orientação, encaminhamentos e laudos. Diante disso, o objetivo do estágio foi precisamente proporcionar ao estudante de Psicologia conhecimentos sobre processos de avaliação psicológica no contexto da Educação Especial. Sobre esse ponto destacamos que:

\begin{abstract}
A avaliação psicológica é um processo técnico e científico realizado com pessoas ou grupos de pessoas que, de acordo com cada área de conhecimento, requer metodologias específicas. Ela é dinâmica e constitui-se em fonte de informações de caráter explicativo sobre os fenômenos psicológicos, com a finalidade de subsidiar os trabalhos nos diferentes campos de atuação do psicólogo, dentre eles, saúde, educação, trabalho e outros setores em que ela se fizer necessária. Trata-se de um estudo que requer um planejamento prévio e cuidadoso, de acordo com a demanda e os fins para os quais a avaliação se destina (NORONHA, 2013, p. 13).
\end{abstract}

Diante dessa definição, reafirmamos que, ao longo desse estágio, com a aprendizagem da avaliação psicológica como alvo principal, não perdemos de vista o anseio pela construção de uma Psicologia capaz de ampliar as possibilidades de análise e intervenção psicológica nas diferentes relações que acontecem na escola, impactando tanto a produção da aprendizagem quanto a própria queixa e a exclusão escolar. Tomamos como referência organizadora o olhar de uma Psicologia que percebe a gênese da aprendizagem, da queixa e da exclusão escolar em sua processualidade e multifatorialidade. Portanto, a concepção de avaliação psicológica que norteou nossas ações foi pautada no contexto desse anseio por colocar a Psicologia e a avaliação psicológica a serviço das múltiplas dimensões, instâncias e relações que constroem uma proposta pedagógica.

Por conseguinte, nesse estágio, os acadêmicos foram conduzidos a atuar em equipe multiprofissional e sob a perspectiva transdisciplinar visando à aprendizagem de procedimentos necessários à elaboração de projetos e instrumentos de avaliação. Ademais, foram instrumentalizados para o planejamento e o desenvolvimento de propostas de intervenção psicológica atreladas às pessoas com deficiência, com transtornos globais do desenvolvimento, altas habilidades/superdotação e dislexia, vislumbrando a promoção de sua inclusão social e educacional.

Os procedimentos de avaliação psicológica, com seus desdobramentos, aconteceram em locais adequados disponibilizados pela Reitoria da UFGD ao Núcleo Multidisciplinar para a Inclusão e Acessibilidade - NuMIAc/UFGD. Sob essa circunstância, os acadêmicos acolheram o referido alunado e, por meio de entrevistas, empregaram técnicas de observação e lançaram mão de instrumentos de avaliação, alcançando informações capazes de subsidiar a elaboração de projetos de intervenção não apenas psicológica, mas também pedagógica e até mesmo organizacional.

Durante o planejamento e o desempenho dos atendimentos, os acadêmicos utilizaram como recurso norteador, para obtenção e síntese de informações, um roteiro desenvolvido por docentes do Programa de Pós-Graduação em Educação Especial da Universidade Estadual Paulista "Júlio de Mesquita", a fim de auxiliar educadores no processo de elaboração do plano de desenvolvimento individual para o atendimento educacional especializado (POKER et al., 2013). Assim sendo, as informações recolhidas foram sistematizadas por meio de Planos Individuais de Desenvolvimento (PDI) adequados à proposta do Atendimento Educacional Especializado (AEE). No total, cinco estagiários dedicaram-se ao estágio durante um semestre inteiro. Ao longo desse período, entrevistaram trinta e quatro estudantes e dois docentes autodeclarados, apresentando em sua maioria demandas relativas à dislexia, à deficiência intelectual, à baixa visão e, sobretudo, à surdez. 
Os estudantes surdos, que atualmente compõem as duas turmas de Licenciatura em Letras Libras, geraram uma demanda para o Núcleo de Inclusão e Acessibilidade da UFGD (NuMIAc) no preenchimento do Plano Individual de Desenvolvimento (PDI), em razão da própria natureza do curso, na garantia das vagas prioritárias, em que todos se autodeclararam com necessidades educacionais especiais.

Um alerta e um desafio que se evidenciaram entre o encontro dos estudantes dos cursos de Psicologia e de Letras Libras da UFGD foi o fato de que, nessa atividade, os estagiários da Psicologia não conseguiam se comunicar com os seus entrevistados surdos do Letras Libras. Esse fato gerou angústia e comoção provocadas pela falta do saber necessário para promover uma intenção comunicativa de qualidade em língua de sinais, por um lado, pela falta de habilidade linguística em Libras dos estudantes da Psicologia e, de lado, pela falta de intérpretes de línguas de sinais suficientes na instituição.

Nesse momento, evidenciou-se a necessidade de um número maior de intérpretes na Instituição para atender não só o momento das entrevistas para o PDI, mas todas as atividades e necessidades em que os estudantes surdos possam precisar de acessibilidade na comunicação. Intérpretes de língua de sinais têm sido requisitados cada vez mais na medida em que os surdos avançam conquistando espaços na universidade, e esse profissional passa também a ser mais qualificado e reconhecido.

Para atender a essas novas exigências de qualificação na atuação da interpretação de Libras, a UFGD criou o curso de Bacharelado em Letras Libras para formação específica desse profissional, e seu primeiro vestibular ocorrerá ainda no ano de 2018. Portanto, o reconhecimento e a qualificação desse profissional podem acompanhar o mesmo ritmo dos avanços dos surdos aos espaços no Ensino Superior e, consequentemente, em toda a sociedade. Entretanto, até que essas iniciativas se tornassem realidade, intérpretes da universidade e docentes bilíngues do curso de Letras Libras desempenharam as mediações necessárias para que as entrevistas psicológicas pudessem ser realizadas.

\section{As aprendizagens}

As aprendizagens geradas pelas diversas situações vivenciadas durante as atividades do estágio levaram-nos a diferentes reflexões relacionadas ao processo formativo de psicólogos, e elas também estavam presentes no discurso dos estagiários ${ }^{1}$ quando avaliaram o processo experienciado. Entre as ponderações que se destacaram constam aquelas relacionadas ao desafio implicado no próprio processo de organização de um projeto pedagógico para que ele se tornasse capaz de produzir uma prática formativa e coerente. Uma prática na qual o compromisso com a promoção da inclusão a atravessasse e norteasse desde as ações mais simples que a constituem, por exemplo, a apresentação de uma área de conhecimento como possibilidade de atuação profissional:

\footnotetext{
A principal aprendizagem, para mim, foi de encarar novas oportunidades de estudo e experiências novas, lidando com um público que o curso ainda não tinha me proporcionado. Além de entender melhor as especificidades de uma Psicologia voltada à Educação Especial (Bárbara Gomes de Matos, estagiária na disciplina Estágio em Psicodiagnóstico - Avaliação Psicológica no Contexto da Educação Especial).
}

\footnotetext{
${ }^{1}$ Participaram como estagiários nesta experiência os seguintes alunos: Aline Pereira da Silva, Bárbara Gomes de Matos, Janiellyn Alves Gonçalves, José de Oliveira Costa e Miriane de Oliveira Pereira.
} 

estudante:

$\mathrm{Na}$ vinculação das novas possibilidades abertas ao processo de formação pessoal do

\begin{abstract}
Quando iniciamos, havia o medo do desconhecido visto que eu pessoalmente nunca tinha nem me aproximado de pessoas surdas. Para mim foi riquíssimo perceber que posso conversar com alguém que não é da comunidade oralista. Estes que entrevistei acabaram por despertar um desejo de aprender a língua de sinais e ao mesmo tempo que me fizeram saber que eles têm uma representação de mundo para nos ensinar. Quando sentamos para conversar com estes sujeitos pudemos verificar que somos nós que fazemos os nossos preconceitos (José de Oliveira Costa, estagiário na disciplina Estágio em Psicodiagnóstico - Avaliação Psicológica no Contexto da Educação Especial).

Construir uma escuta e uma escrita que se afastasse de termos preconceituosos ou limitadores para dar lugar a um espaço de empatia e acolhimento. Foi difícil, mas acredito que superei graças às leituras, supervisões e reflexão (Aline Pereira da Silva, estagiária na disciplina Estágio em Psicodiagnóstico - Avaliação Psicológica no Contexto da Educação Especial).
\end{abstract}

As vivências permitidas pelo estágio foram importantes para que os acadêmicos compreendessem muitas necessidades que permeiam a formação de psicólogos para a área da Educação Especial e para a atuação, de maneira ampla, sob a perspectiva da inclusão social. Qual o local, as condições e os procedimentos adequados para se abrir escuta psicológica sobre questões relativas à aprendizagem escolar? O conhecimento formal é suficiente para se produzirem práticas inclusivas, ou trata-se de um tipo de aprendizagem que implica modificações de condutas pessoais do próprio profissional em formação? Que desafios estão presentes no preparo de estudantes de Psicologia para a atuação em Educação Especial, ainda que sob a perspectiva inclusiva? Ademais, possibilitaram o conhecimento das possibilidades e limites das universidades para a realização dessa formação:

\begin{abstract}
Aprendemos [dentro da própria universidade] que algumas dificuldades de aprendizagem do aluno com deficiência são decorrentes da própria "Cultura Acadêmica". Esta, em algum momento, valoriza um determinado padrão, um "jeito acadêmico ideal de ser" que prejudica o pleno acolhimento do aluno, não apenas daquele com deficiência e, portanto, por ele não se enquadrar, por ser diferente dos demais alunos, vai esbarrar em preconceitos e crenças tanto dos professores como também dos colegas de sala, fazendo com que os potenciais do aluno sejam subestimados (Janiellyn Alves Gonçalves, estagiária na disciplina Estágio em Psicodiagnóstico - Avaliação Psicológica no Contexto da Educação Especial).
\end{abstract}

Percepções como essas obrigaram-nos a retornar o olhar para nós mesmos e propiciaram aos estagiários e à própria instituição condições para repensar sobre adequações, ajustes e adaptações que precisam ser providenciados tanto do ponto de vista estrutural quanto da conduta e da cultura institucional, a fim de que se promovam condições de acessibilidade às diferentes oportunidades de aprendizagem e experiências culturais que uma universidade pode oferecer efetivamente a todas as pessoas.

No entanto, talvez as mais significativas oportunidades de aprendizagem geradas por esse estágio tenham sido derivadas do encontro entre os acadêmicos de Psicologia e a comunidade de alunos surdos matriculados no Curso de Letras Libras da UFGD:

Principal aprendizagem: difícil eleger uma como principal, pois todas foram importantes! Vou destacar a aprendizagem sobre o encontro com o desconhecido. A 
comunidade surda era, até então, distante da minha realidade. Ter o contato, entender suas histórias de vida e aprender sobre a cultura surda e sobre a inclusão trouxe para mim um novo olhar e o entendimento de que a visibilidade é aliada da inclusão (Aline Pereira da Silva, estagiária na disciplina Estágio em Psicodiagnóstico - Avaliação Psicológica no Contexto da Educação Especial).

A principal dificuldade foi de não saber a língua de sinais, e assim acabou-se por criar uma certa ansiedade no momento da entrevista (José de Oliveira Costa, estagiário na disciplina Estágio em Psicodiagnóstico - Avaliação Psicológica no Contexto da Educação Especial).

Minha principal dificuldade foi a insegurança das primeiras entrevistas, principalmente pela presença do intérprete, que num primeiro momento me deixou insegura, mas me fez perceber a importância de aprender a Libras (Miriane de Oliveira Pereira, estagiária na disciplina Estágio em Psicodiagnóstico - Avaliação Psicológica no Contexto da Educação Especial).

Este encontro converteu-se em fonte de inúmeras inquietações sobre a qualidade da formação profissional que está sendo alcançada pelos estudantes de Psicologia: Como abrir escuta psicológica a usuários de Libras, como primeira língua, quando quem realiza o atendimento não domina esse recurso? Como introduzir um intérprete de Libras no cenário do atendimento psicológico? O intérprete de Libras tem formação adequada ou suficiente para atuar nesse cenário de atendimento? A presença do intérprete interfere no processo de avaliação realizado, altera resultados? As orientações do Conselho Federal de Psicologia são suficientes para promover acessibilidade e garantir conduta ética ao mesmo tempo? Como transformar esse atendimento em uma oportunidade efetiva de benefício ao usuário?

Construir respostas, ainda que parciais e provisórias, a cada um dos questionamentos que emergiram ao longo do processo representa grande parte da importância do trabalho realizado. Contudo, em nosso entendimento, a riqueza da experiência vivida centra-se justamente na oportunidade que a parceria entre o Curso de Psicologia e o NuMIAc engendrou. Pelas ações desempenhadas em conjunto pode-se observar a transformação, a ampliação e a aproximação da formação inicial de psicólogos ao ideal de construção de uma sociedade cada vez menos desigual. Ao mesmo tempo, as próprias ações executadas e as indagações que delas derivaram abriram oportunidade de reorganização estrutural, pedagógica, cultural e organizacional da própria universidade que as abriga. Esse é o sentido da Psicologia aplicada à Educação Especial - ressignificar as queixas escolares, compreendê-las processual e multifatorialmente, a fim de promover coletivamente condições para dirimi-las.

No tocante à formação de professores de Libras pelo curso de Licenciatura em Letras Libras, os estudantes surdos, atendidos pelos estagiários da Psicologia na construção do PDI, contribuíram para suscitar reflexões sobre o atendimento educacional especializado necessário que possa contribuir para a conclusão do curso com êxito, tendo as suas especificidades atendidas durante o curso. Entre estas podemos citar a dificuldade com a língua portuguesa como segunda língua na sua leitura e escrita pelos estudantes surdos para que possam compreender os conteúdos do curso, assim como a produção de suas atividades e construção do seu conhecimento registrado tanto em Libras quanto na língua portuguesa. Isso denunciou a dificuldade da Universidade de oferecer profissionais habilitados na oferta de português como segunda língua, como ações do Atendimento Educacional Especializado (AEE), assim como acompanhamento nas dificuldades dos surdos na aquisição conceitual das disciplinas do curso ou, ainda, de profissionais que possam auxiliar o surdo com baixa visão que necessita de adaptações e recursos específicos para acompanhar as atividades do curso.

Essa experiência contribuiu para a reflexão a respeito da inclusão dos estudantes surdos no Ensino Superior, em que apenas a presença do intérprete de Libras ou do material bilíngue não é suficiente para a promoção de uma inclusão de qualidade, sendo necessário promover 
uma consciência inclusiva de acolhimento em toda a Universidade. Não basta ter Libras na Universidade. É preciso ter consciência de que a acessibilidade será promovida quando houver mudanças na mentalidade e no comportamento das pessoas sobre inclusão e respeito às diferenças, sejam elas linguísticas ou não.

Outra aprendizagem significativa foi a sensibilização entre os professores bilíngues do curso de Letras Libras para a oferta de cursos de Extensão de Libras para as diferentes áreas do conhecimento da Universidade e comunidade externa da cidade de Dourados e região. Isso culminou na realização de um projeto de extensão para o ensino de Libras para psicólogos, num curso carinhosamente apelidado de Psicolibras, atendendo tanto estudantes e docentes de Psicologia quanto psicólogos formados.

Portanto, a inclusão educacional de pessoas com deficiências tem ganhado cada vez mais visibilidade na comunidade universitária e na sociedade em geral, por meio de experiências como essa, em que encontros promissores entre diferentes áreas do conhecimento convergem para uma busca de uma educação inclusiva de qualidade no Ensino Superior.

\section{REFERENCIAS}

ANTUNES, Mitsuko Aparecida Makino. Psicologia escolar e educacional: história, compromissos e perspectivas. Psicologia Escolar e Educacional, v. 12, n. 2, p. 469-475, 2008.

ASBAHR, Flávia da Silva Ferreira. Notas sobre o ensino de psicologia escolar em uma concepção crítica. Psicologia: Ensino \& Formação, v. 5, n. 1, p. 20-31, 2014.

BRASIL. Secretaria de Educação Especial. Lei n. ${ }^{\circ}$ 10.436, de 24 de abril de 2002. Dispõe sobre a Língua Brasileira de Sinais - Libras e dá outras providências. Diário Oficial [da] República Federativa do Brasil, Brasília, 25 abr. 2002, p. 23. Regulamentada pelo Decreto n. ${ }^{\circ}$ 5.626, de 22 de dezembro de 2005.

BRASIL. Decreto n. ${ }^{\circ}$ 5.626, de 22 de dezembro de 2005. Regulamenta a Lei n. ${ }^{\circ} 10.436$, de 24 de abril de 2002, que dispõe sobre a Língua Brasileira de Sinais - Libras, e o art. 18 da Lei n. ${ }^{\circ}$ 10.098, de 19 de dezembro de 2000. Diário Oficial [da] República Federativa do Brasil, Brasília, 23 dez. 2005, p. 28.

CHAVEIRO, Neuma; ALVES BARBOSA, Maria; PORTO, Celmo Celeno; BOUTTELET MUNARI, Denise; MEDEIROS, Marcelo; REIS DUARTE, Soraya Bianca. Atendimento à pessoa surda que utiliza a língua de sinais, na perspectiva do profissional da Saúde. Cogitare Enfermagem [online] 2010, 15.20 Disponível <http://www.redalyc.org/articulo.oa?id=483648973007>. Acesso em: 13 mar. 2018.

MENDONZA, Carmem E. Flores. Estudo exploratório sobre a atuação dos psicólogos escolares que trabalham com populações especiais em Mato Grosso do Sul. Estudos de Psicologia, v. 14, n. 1, 1997. 
NORONHA, A. P. P. Cartilha Avaliação Psicológica - 2013. Brasília/DF: Conselho Federal de Psicologia, 2013. Disponível em: 〈http://www.cfp.org.br>.

PATTO, Maria Helena Souza. Ciência e política na primeira república: origens da psicologia escolar. Mnemosine, São Paulo, v. 1, n. 0, 2004.

POKER, Rosimar Bortolini et al. Plano de desenvolvimento individual para o atendimento educacional especializado. Marília: Cultura Acadêmica/Oficina Universitária, 2013.

QUADROS, Ronice Müller de. O tradutor e intérprete de língua brasileira de sinais e língua portuguesa. Secretaria de Educação Especial; Programa Nacional de Apoio à Educação de Surdos. Brasília: MEC; SEESP, 2004.

(org.). Letras Libras: ontem, hoje e amanhã. Florianópolis: Ed. da UFSC, 2014.

SKLIAR, Carlos. A surdez: um olhar sobre as diferenças. Porto Alegre: Dimensão, 1998.

SOUSA BRAZ-AQUINO, Fabíola de; LUCENA FERREIRA, Ingrid Rayssa; ALMEIDA CAVALCANTE, Lorena de. Concepções e práticas de psicólogos escolares e docentes acerca da inclusão escolar. Psicologia: Ciência e Profissão, v. 36, n. 2, 2016.

SOUZA, Marilene Proença Rebello de. Psicologia escolar e políticas públicas em Educação: desafios contemporâneos. Em Aberto, Brasília, v. 23, n. 83, p. 107-128, mar. 2010.

UNIVERSIDADE FEDERAL DA GRANDE DOURADOS. Projeto Pedagógico do Curso de Graduação - Bacharelado em Psicologia/Formação de Psicólogo e Projeto Complementar Licenciatura em Psicologia. Dourados, MS, 2017. Disponível em: $<$ http://files.ufgd.edu.br/arquivos/arquivos/78/COGRAD/PROJETO\%20PPC\%20Psicologia\% 20-\%202017.pdf>. Acesso em: 14 mar. 2017.

VIANA, Meire Nunes. Interfaces entre a Psicologia e a Educação: reflexões sobre a atuação em Psicologia Escolar. In: ; FRANCISCHINI, Rosângela. Psicologia Escolar: que fazer é esse? Brasília: CFP, 2016.

Recebido em:30/09/2017

Aceito em: 25/01/2018 